\title{
Site and mechanism of pain perception with oesophageal balloon distension and intravenous edrophonium in patients with oesophageal chest pain
}

\author{
J S de Caestecker, Anne Pryde, R C Heading
}

\begin{abstract}
Ten healthy volunteers and 13 patients with oesophageal motility disorders whose primary presenting complaint was chest pain were studied by distending an intraoesophageal balloon in $1 \mathrm{ml}$ steps to the point of a sensation of discomfort. The net balloon pressure (intraballoon pressure when inflated within the oesophagus minus the pressure recorded at the same volume outside the patient) was measured at each volume increment and the distension volume at the perception of discomfort was noted. The measurements were repeated after intravenous injection of edrophonium $(80 \mu \mathrm{g} / \mathrm{kg})$ and again after $1.2 \mathrm{mg}$ intravenous atropine. Oesophageal wall compliance was similar in patients and controls, and the two groups showed a similar effect of decreased compliance with edrophonium and increased compliance after atropine. There were no significant differences between patients and controls of distending volume at perception of discomfort. Edrophonium, however, resulted in a significant reduction in distension threshold for pain $(p<0.03)$ in patients. A similar though non-significant trend was seen in controls. In both controls and patients, distension volume for pain production after atropine was significantly $(p<0.01)$ higher than after edrophonium. From these results and other published data, we suggest that the pain receptor for noxious stretch and after edrophonium challenge is likely to be an 'in series' mechanoreceptor located in oesophageal longitudinal muscle.
\end{abstract}

Intravenous edrophonium administered during oesophageal manometry has been advocated as a useful test to provoke symptoms in patients with angina like chest pain suspected to be of oesophageal origin. ${ }^{13}$ It has been reported to provoke familiar chest pain in about a third of such patients. ${ }^{3+}$ Some regard the mere occurrence of symptoms with the drug as diagnostic of oesophageal pain, ${ }^{3}$ while others require both symptoms and manometric change. ${ }^{+}$In healthy individuals as well as patients with oesophageal motility disorders, edrophonium causes a short lived increase in peristaltic amplitude and duration, sometimes in association with non-peristaltic contractions. ${ }^{+6}$
The mechanism of production of pain with edrophonium is unclear: patients who develop their typical symptoms with the drug have a significantly greater increase in peristaltic duration (but not amplitude) than those who do not. ${ }^{17}$ A large overlap exists, however, so that some patients with large increases in peristaltic duration do not have symptoms whereas others develop symptoms with little manometric change. Furthermore, provoked chest pain is frequently continuous over several minutes while oesophageal pressure waves are only observed intermittently. ${ }^{17} \mathrm{~A}$ possible reason for this failure to correlate pain and manometric findings is that pain does not directly result from abnormal motility but rather from heightened sensory perception. ${ }^{8}$ This could result in otherwise painless 'physiological' stimuli being perceived as painful. It is possible and likely that the manometric changes observed in some patients are modulated by the sensory receptors, probably by an axon reflex influence on the effector neurones of the myenteric plexus. ${ }^{8}$

Balloons have a long history of application to the study of oesophageal pain. ${ }^{9-16}$ The use of oesophageal balloons has recently been revived ${ }^{17} 18$ after a long lapse, perhaps resulting from the observation that patients with documented ischaemic heart disease could not differentiate between the pain of their exertional angina and that induced by oesophageal balloon distension (despite the lack of electrocardiographic changes during balloon induced pain). ${ }^{13}$ These reservations persist, ${ }^{19}$ particularly now that microvascular angina has emerged as an alternative explanation for chest pain in patients with chest pain but anatomically normal coronary arteries. ${ }^{20}$ Nevertheless, oesophageal balloon distension can reproduce pain in 40 to $60 \%$ of patients with non-cardiac chest pain suspected to be of oesophageal origin. ${ }^{1721}$ There is some evidence that these individuals have increased oesophageal sensitivity to stretch,," while others have pointed out that such patients show abnormalities of the oesophageal peristaltic reflex during balloon induced pain. ${ }^{1 \times}$

The purpose of this investigation was to study the effects of edrophonium and atropine on the perception of discomfort and oesophageal wall compliance during oesophageal balloon distension in an attempt to throw some light on the mechanisms and site of action of edrophonium

Royal Infirmary,

J S de Caestecker

5 August 199
} 
and balloon distension as provocative manoeuvres.

\section{Methods}

SUBJECTS

Ten healthy volunteers were recruited (seven men and three women, mean age 28 (SD 4.8) years). Three had experienced occasional heartburn less than once a month; otherwise no volunteer had any oesophageal or gastrointestinal symptoms.

Thirteen patients agreed to participate (five men and three women, mean age 48 (SD 8) years. All had been found to have oesophageal motility disorders during previous oesophageal manometry and all had had a normal endoscopic examination of the oesophagus. The manometric diagnoses were: diffuse oesophageal spasm (six), high amplitude and/or prolonged duraton peristalsis (six patients - three had also experienced their typical symptoms with provocation tests during manometry) and vigorous achalasia (one). This latter patient had previously undergone forceful pneumatic dilatation of the cardia and had been shown radiologically not to have a dilated oesophagus. All patients had originally presented with chest pain, 10 also complaining of dysphagia, a further two of odynophagia and two of heartburn (distinct from their chest pain) in addition. At the time of the study, 12 of the 13 patients were still symptomatic.

An Arndorfer ESM3 polyvinyl multilumen oesophageal manometry catheter connected to a low compliance constant water perfusion pump (Arndorfer Medical Specialties Inc, Greendale, Wisconsin, USA) was adapted by tying a rubber balloon over one of the recording ports so that it was placed $10 \mathrm{~cm}$ above the distal recording port. The balloon was fashioned from a latex rubber finger cot cut to $3 \mathrm{~cm}$ in length. ${ }^{21}$ The ends were secured to the polyvinyl tube by winding and tying a silk suture tightly around either end. The loose ends were trimmed and a silicone glue seal applied to make the balloon airtight. The balloon channel was filled with air and connected to an external pressure transducer and chart recorder

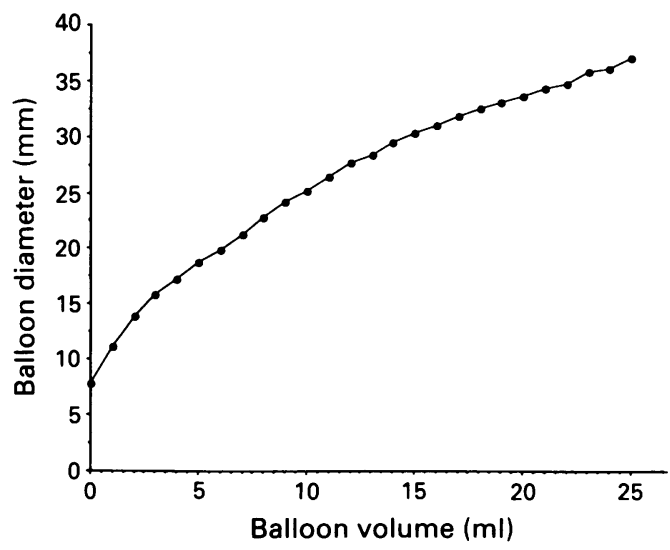

Figure 1: Volume - diameter relationship for the balloon used in all the studies. The diameter of the balloon at its widest point was measured using a micrometer. The individual data points are the mean of 2 separate benchtop inflations; the mean difference between the 2 measurements at each volume increment was $0.4 \mathrm{~mm}$.
(Elcomatic, Neilston, Glasgow) using a three way tap. This enabled inflation of the balloon with air in steps of $1 \mathrm{ml}$, and measurement of intra-balloon pressure at each step.

Inflations were carried out on the bench in air before each patient study, and the balloon was checked in water for leaks on each occasion. The same balloon was used for all experiments in patients and controls, as preliminary trials indicated that different sized balloons or even balloons of the same size constructed out of similar latex rubber finger cots had different compliances. This problem has been noted previously..$^{22}$ For the balloon used in the studies, the relationship between balloon diameter (measured with a micrometer) and volume during benchtop inflations, although not entirely linear, showed no evidence of flattening over the range of volumes used during intraoesophageal inflations (Fig 1). Although no in vivo measurements were made, two studies have indicated that during inflation in the oesophagus, similar rubber balloons are only slightly deformed. ${ }^{21} 23$

For patient studies, the deflated balloon and manometry catheter assembly was passed through the nose and positioned so that the balloon lay $9 \mathrm{~cm}$ above the respiratory inversion point of the lower oesophageal sphincter (identified by a monometric recording channel $1 \mathrm{~cm}$ proximal to the distal channel). The balloon was inflated in $1 \mathrm{ml}$ steps in such a fashion that the patient did not know when air was being added to the balloon, until a continuous sensation of discomfort was felt. A short period was allowed to elapse after each step of the inflation for the balloon pressure tracing to stabilise, but the balloon was not deflated between steps. Once a stable pressure trace was observed, the minimum intraballoon pressure at each volume step was measured with reference to the basal pressure reading when the balloon had been deflated within the oesophagus.

Dry swallows were sensed by a hand on the patient's throat so that each could be marked on the chart. The patient was instructed before each period of balloon inflation to report the point at which any abnormal chest or back sensation occurred, and also the point at which this became definitely uncomfortable. No attempt was made to prompt the patients who were required to volunteer the information requested. The point at which definite discomfort was reported was recorded on the chart. In the case of patients with proven motility disorders, each was asked whether the discomfort resembled their spontaneous symptoms. The balloon was deflated once this point had been reached and patients were asked to describe the location and character of the symptom that had been provoked.

In each case, the same procedure was repeated after intravenous injection of edrophonium $(80 \mu \mathrm{g} / \mathrm{kg})$. In four subjects, an end point of discomfort was not achieved after edrophonium, as the balloon had to be deflated at the patient's request because of intolerable nausea or nasal discomfort from aboral balloon traction. Twenty five to 30 minutes after edrophonium, atropine $1.2 \mathrm{mg}$ was administered intravenously and the balloon inflation procedure repeated. In some instances, more than one inflation procedure 


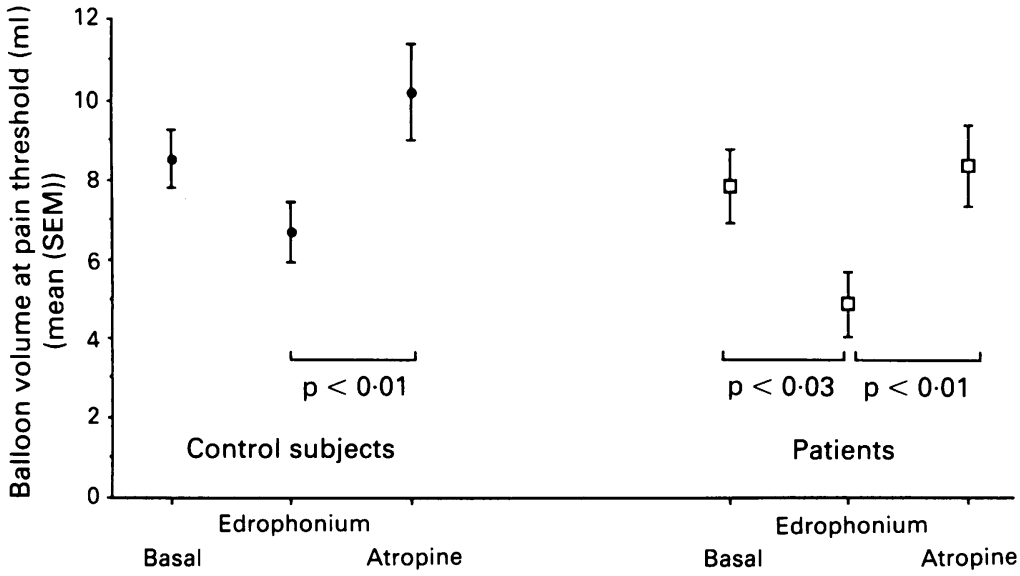

Figure 2: Mean (SE) intraoesophageal balloon volume at the point of pain perception in controls and patients during initial (basal) inflation, after edrophonium and after atropine. Significant differences (by ANOVA) are shown. No significant differences were found between patients and controls.

was carried out during each stage of the procedure to assess the reproducibility of the results. The time in minutes taken for each inflation (mean (SD)) was, for control subjects and patients respectively, $3 \cdot 1(1 \cdot 2)$ and $3 \cdot 1(1 \cdot 1)$ for the basal period, $3 \cdot 0(0 \cdot 9)$ and $2 \cdot 7(1 \cdot 4)$ after edrophonium and $3 \cdot 1(1 \cdot 4)$ and $3 \cdot 3(1 \cdot 7)$ after atropine. In particular, in no subject did the inflation period exceed four minutes 40 seconds after edrophonium, an important consideration as this drug has a short duration of action.

During each recording, three channels (one at $5 \mathrm{~cm}$ and one at $10 \mathrm{~cm}$ above the balloon and one in the lower oesophageal sphincter) were perfused with water from the Arndorfer hydraulic capillary infusion pump. A continuous record of oesophageal motor activity at these points was obtained. Oesophageal motor activity proximal to the balloon was assessed qualitatively, but no attempt was made to measure the amplitude or duration of pressure waves, as all swallows were 'dry'. Because the recording channel in the lower oesophageal sphincter tended to slip into the stomach (presumably because of oesophageal shortening known to occur with distension of the oesophageal body), ${ }^{24} 25$ readings from this channel were not analysed.

After each experiment, the observed intraballoon pressure at each volume step during benchtop inflation was subtracted from the cor-
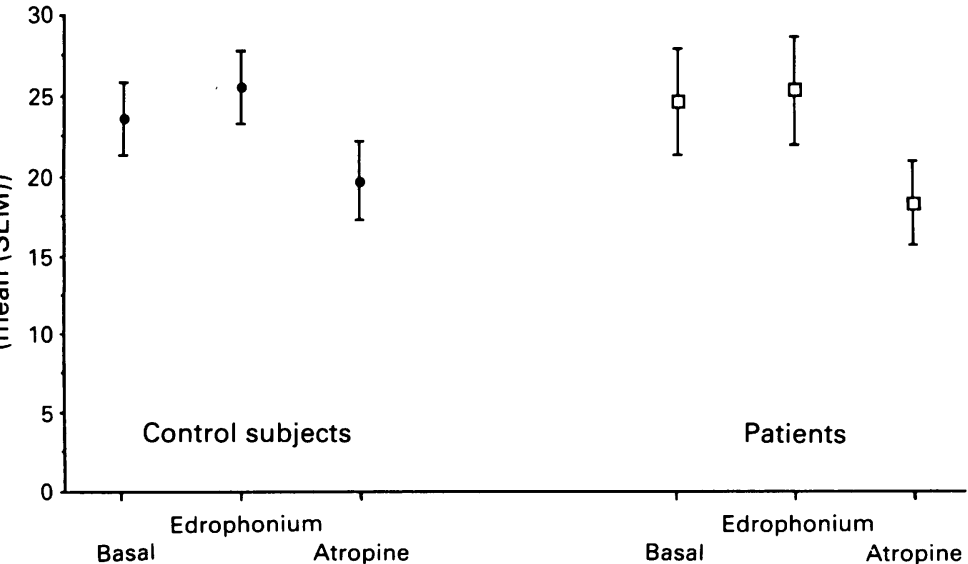

Figure 3: Mean (SE) net intraoesophageal balloon pressure at the point of pain perception in controls and patients during initial (basal) inflation, after edrophonium and after atropine. No significant differences were found (ANOVA). responding value during intraoesophageal distension to obtain a more accurate reflection of the contribution to the measured balloon pressure resulting from the oesophageal wall. The pressure measurements obtained are termed 'net balloon pressure'. According to Laplace's law, tension $(\mathrm{T})$ in the wall of a cylinder is given by the relationship $\mathrm{T}=\mathrm{p} \times \mathrm{r}$, where $\mathrm{p}=$ intraluminal pressure and $r=$ the radius of the cylinder. As oesophageal diameter was not measured, however, the tension could not be calculated, so the pressure measurements are only an indirect reflection of oesophageal mural tension.

\section{STATISTICAL ANALYSIS}

Statistical tests used included analysis of variance (either repeated measures or factorial, depending on whether paired or unpaired samples were being compared). Where significant overall differences were found, Scheffe's test was used as a multiple range test to locate the differences, with an adjustment of the $p$ value for each comparison to reduce the chance of a type I error. Pearson's product moment correlation coefficient was calculated as a measure of reproducibility. A p value of $<0.05$ was taken to indicate a significant result.

\section{Results}

\section{SITE AND NATURE OF DISCOMFORT}

Discomfort was experienced by control subjects retrosternally in six, with radiation to the back (two), abdominal right upper quadrant (two) and throat (one). Two experienced throat discomfort only, one back pain alone and one pain in the back and right upper quadrant. The pain was described as burning by one subject, and by the others as a 'pressure' or 'ache'.

Among the 13 patients, eight experienced retrosternal discomfort only. In three others, the discomfort was felt in the back as well as restrosternally and in the final two, the throat was the only site of discomfort. Two patients described the pain as heartburn and five (38\%) felt the pain during the initial inflation period (without administered drugs) was the same as their usual spontaneous symptom. Of these five, three were cases of high amplitude and/or prolonged duration peristalsis and two had diffuse oesophageal spasm.

Several patients and control subjects commented that the discomfort was initially felt at one site but, on subsequent balloon inflations, was also experienced at another site. A minority of patients and controls noted that the symptoms worsened transiently coincident with peristaltic waves reaching the site of balloon distension.

\section{OESOPHAGEAL MOTOR ACTIVITY DURING BALLOON}

\section{INFLATION}

This was only analysed qualitatively, as wet swallows were impossible with the oesophagus occluded by a balloon. Dry swallows were permitted, but are known to give variable results in terms of patterns of pressure change and amplitude or duration of pressure waves. ${ }^{26}{ }^{27}$ 
In the majority $(60-80 \%$ - the proportion varying during different phases of the study) of controls, all pressure waves were peristaltic during the balloon inflation, with a few (20-30\%) having spontaneous non-propagated waves occurring more than once a minute during balloon inflation. In only one did the nonperistaltic activity occur only during discomfort.

Not surprisingly, in less than half $(46 \%)$ of the patients was pressure activity only peristaltic, as seven were known to have either diffuse oesophageal spasm or vigorous achalasia. The proportion with peristaltic activity but no abnormal pressure waves increased following edrophonium to $69 \%$. Although a high proportion (31-46\%) of patients exhibited frequent spontaneous non-peristaltic waves, in only a small number $(8-23 \%)$ did this abnormality coincide with the development of symptoms. Even fewer controls exhibited this feature.

Non-swallow related peristaltic waves proximal to the distending balloon were only observed in $40 \%$ of patients and controls, being reduced or abolished by atropine. The infrequency of these waves may be attributable to the fact that patients were allowed to swallow at will, resulting in inhibition of this activity. Atropine diminished peristaltic amplitude in all patients and controls, causing aperistalsis in $23 \%$ and $40 \%$ respectively. A steady rise in baseline proximal intraoesophageal pressure to between 6 and $12 \mathrm{~mm} \mathrm{Hg}$ above basal pressure was observed in $10 \%$ of controls (but only in one of the 13 patients) during balloon inflation, being more frequently seen ( $40 \%$ of controls) after atropine. This occurred independently of the development of symptoms, and represents a phenomenon already reported by Enzmann and colleagues. ${ }^{28}$ Finally, multipeaked peristaltic waves were observed in $31 \%$ of patients (but not controls) after edrophonium, always independent of symptoms.

\section{RELATIONSHIP OF BALLOON VOLUME AND PRESSURE TO DISCOMFORT}

The balloon distension volumes and pressures at which discomfort was first perceived by controls and patients is shown in Figures 2 and 3. For patients and controls considered together, there was a significant overall difference in volumes at first perception of pain by ANOVA $(\mathrm{f}=2.51$; $p<0.02)$, but not for pressure $(f=1 \cdot 09 ; p>0 \cdot 3)$. Using Scheffe's multiple range test, mean inflation volume at perception of discomfort was significantly lower for patients after edrophonium than after either atropine $(p<0.01)$ or initial basal inflation period before drugs were administered ( $p<0.03$; Fig 2). A significant reduction was found in controls in balloon volumes to produce discomfort after edrophonium compared with balloon distension after atropine $(\mathrm{p}<0.01$; Fig 2$)$; although there was a trend for a reduction in distension threshold with edrophonium compared with basal inflation, this was not statistically significant in the controls. No significant differences in threshold balloon volumes at perception of discomfort were apparent between controls and patients with chest pain. There was a non-significant trend for lower intraballoon pressures at the perception of discomfort in controls and patients after atropine compared to basal and post edrophonium periods (Fig 3).

The reproducibility of the measurement of balloon volume and pressure at first perception of discomfort was assessed by comparing duplicate balloon inflations which were carried out on a total of 45 occasions. Reproducible results were obtained for volume measurement at the first perception of discomfort $(\mathrm{r}=0.89 ; \mathrm{p}<0.0001)$ but less so for pressure $(r=0.61 ; p<0 \cdot 0001)$.

\section{EFFECTS OF EDROPHONIUM AND ATROPINE ON} OESOPHAGEAL COMPLIANCE

Net intraoesophageal balloon pressure values are shown in Figures 4 to 6 over the range 1 to $10 \mathrm{ml}$ of air introduced into the balloon. Results for balloon volumes above $10 \mathrm{ml}$ are not given, because the number of control and patient volunteers became too few for meaningful comparison.

An overall comparison was performed between six sets of values (three for patients, three for control subjects) at each balloon volume in the range 1 to $10 \mathrm{ml}$ using one way analysis of variance. Significant overall differences were found at 1 and $2 \mathrm{ml}(\mathrm{p}<0.05)$. No other significant differences overall were observed. There did not appear to be any consistent reason for the significant differences observed at 1 and $2 \mathrm{ml}$. Because significant differences could not be detected at other volumes, it seems reasonable to conclude that there were no differences between the patient and control groups with regard to oesophageal compliance resulting from administration of the drugs used. For clarity, the pressure volume relationship is displayed in Figure 4 for the basal inflation period only; there is no consistent difference in oesophageal compliance between the two groups.

Further comparisons were made within groups - that is, for the patients and controls separately, using analysis of variance (repeated measures) with Scheffe's multiple range test to locate significant effects. Although consistent results were not obtained at low volumes ( 1 and $2 \mathrm{ml}$ ) probably because the balloon was not sufficiently distended for the pressure to reflect oesophageal wall tension, and at volumes exceed-

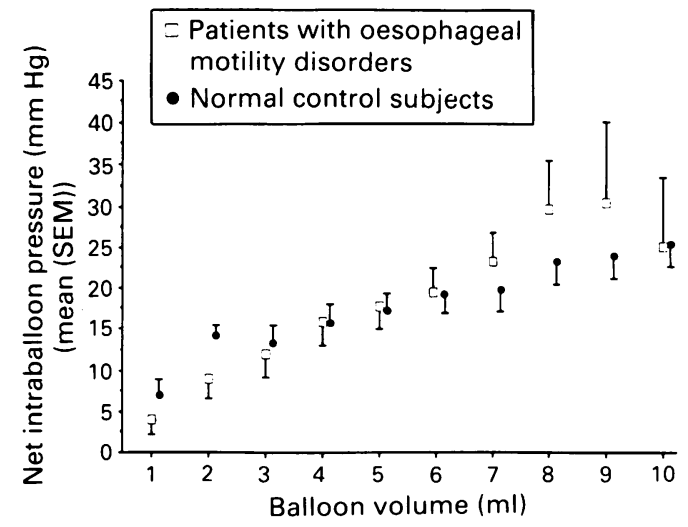

Figure 4: Intraoesophageal balloon net pressure plotted against volume during initial balloon distension before drug administration in controls and patients. There were no significant differences between the 2 groups. 


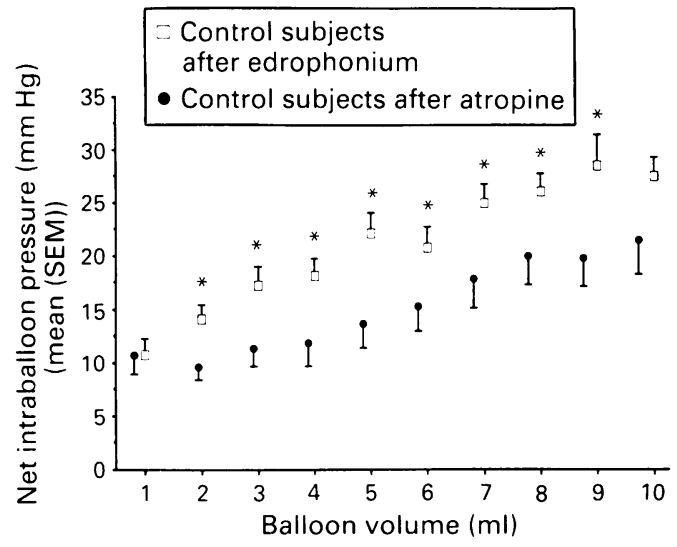

Figure 5: Intraoesophageal balloon net pressure plotted against volume during balloon distension in controls after edrophonium and after atropine.

ing $8 \mathrm{ml}$ (because of small numbers of paired data readings), the overall results for control subjects and patients showed a significantly reduced compliance in edrophonium treated subjects compared with atropine treatment (Figs 4 and 5). There were trends (significant at some volumes but not others) for reduced compliance with edrophonium and increased compliance with atropine compared to basal compliance in patients and controls (data not shown).

Reproducibility of the compliance measurements was assessed by calculating correlation coefficients for paired sets of balloon inflations over the range of volumes for each subject up to that volume at which discomfort was produced. The correlation coefficient varied between 0.76 and $0.97(\mathrm{p}<0.01)$ and were highest after atropine but lowest after edrophonium. This was probably because atropine has a long duration of action, compared with the brief duration of action of edrophonium, so that repeated measurements were made when the effect was waning.

\section{Discussion}

The duration of intraoesophageal balloon distension has an important bearing on the oesophageal motor response. Thus, rapid balloon inflation and deflation characteristically produce proximal stimulation of motor activity both at and above the balloon ${ }^{2329}$ with distal inhibition during inflation while the balloon inflation is maintained. Prolonging the period of distension

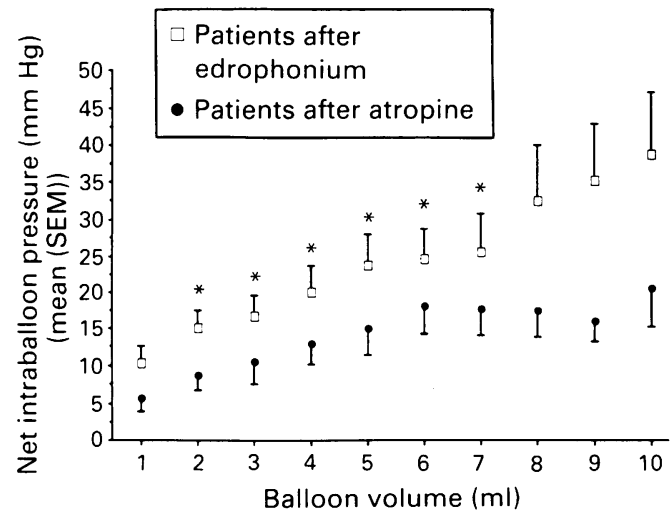

Figure 6: Intraoesophageal balloon net pressure plotted against volume during balloon distension in patients after edrophonium and after atropine. results in a sustained contraction at the level of the balloon ${ }^{2+}$ producing a strong aboral traction force. This is transiently inhibited by swallowing but reinforced by the arrival of the primary peristaltic wave at the balloon..$^{30}$ This contraction, which continues as long as distension is maintained, results in oesophageal shortening below the balloon, and has been shown in the opossum to be the result of the contraction of muscularis mucosae and the longitudinal muscle of the muscularis propria. ${ }^{2+}$ The temporal characteristics of the 'esophageal propulsive force' observed in man by Winship and Zboralske ${ }^{30}$ and the 'duration response' observed by Christensen and Lund $^{2+}$ make it likely that these represent the same phenomenon. This response is abolished by anticholinergic drugs.

In the present study, significant differences were found in oesophageal compliance after edrophonium and atropine. From the foregoing discussion, a likely cause for changes in oesophageal wall compliance measured during balloon distension after administration of drugs affecting cholinergic pathways is contraction of oesophageal muscularis mucosae and longitudinal muscle. ${ }^{2+}$ No differences were found between patients with motility disorders and controls, however, with respect to oesophageal compliance. These findings agree with previous observations in the monkey ${ }^{31}$ and in man..$^{21} 32$

The administration of edrophonium to patients resulted in a significantly lower balloon volume, but not pressure, at pain perception compared with both basal and postatropine balloon distension. A similar significant effect or trend was observed among controls.

These findings may be interpreted as indicating that because administration of a cholinergic blocker reduced oesophageal wall compliance, a critical intraoesophageal pressure (for pain perception) was reached at a lower distension volume, with the converse applying after administration of an anticholinergic agent. This is in keeping with the general observation that changes in gut smooth muscle tension could modulate changes in pain threshold to distension. ${ }^{8}$ We were not able to show a clear difference between patients and controls with respect to this effect.

Oesophageal ischaemia consequent on distension has been suggested as a mechanism for pain production. ${ }^{33}$ If so, cholinergic stimulation could enhance oesophageal wall ischaemia, perhaps simply by allowing a critical oesophageal wall tension inhibiting blood flow to be reached at an earlier stage of distension. Our findings would be compatible with this hypothesis, but other preliminary studies have failed to find evidence of oesophageal ischaemia either in patients during episodes of chest pain ${ }^{3+}$ or in a rabbit model during swallowing before or after intravenous edrophonium..$^{35}$

Can any conclusions be reached from these observations regarding the mode of action of oesophageal balloon distension and intravenous edrophonium when used as provocative agents in patients with non-cardiac chest pain? While our results apply only to patients who have been found to have motility disorders during oesophageal manometry (and so may not necessarily be 
extrapolated to all patients with non-cardiac chest pain), we believe that some conclusions may be drawn.

With regard to balloon distension, motility changes proximal to the balloon did not show any consistent relationship with pain perception. Other work suggests that a proportion of such individuals developing their symptoms during balloon distension have abnormalities distal to the balloon. ${ }^{13}$ Whether such abnormal distal activity is the cause of pain or (as seems more likely) a marker of an abnormal oesophagus is at present not clear.

We could not show abnormally low thresholds to stretch in our patients, but our sample size was small and highly selected. A reduced threshold has been reported by Richter and colleagues in patients with chest pain, ${ }^{21}$ but they studied larger numbers of patients who differed from ours in that although all had non-cardiac chest pain, only a minority had manometric abnormalities. In addition, there are methodological differences in the techniques of balloon inflation, although we do not believe these are likely to have influenced the results. In agreement with the findings of this group, we did not observe any difference in oesophageal compliance between our patients and healthy controls. Furthermore, we did not find any differences between patients and controls in oesophageal wall compliance resulting from cholinergic or anticholinergic drug administration.

Our results are consistent with the hypothesis that stretch sensitive mechanoreceptors located in longitudinally oriented muscle are involved in the perception of pain induced by balloon distension. It has recently been shown that mechanoreceptors with the electrophysiological characteristics of nociceptors appear to be located in series' with oesophageal longitudinal muscle but not circular muscle. ${ }^{36}$ Mechanoreceptors in circular muscle layers by contrast do not appear to have the characteristics of nociceptors, ${ }^{37}$ responding maximally only to physiological changes in tension that result from peristaltic activity.

The observation that edrophonium resulted in a lowering of the pain threshold to distension and also in decreased oesophageal wall compliance (which we have argued represents an effect on longitudinal muscle) prompts the speculation that pain developing with this drug is sensed by the same receptors as those responding to balloon distension. If so, it would explain why there appears not to be a close correlation between the manometric changes which occur after the drug and the appearance of symptoms. Longitudinal muscle contraction is not directly recorded by conventional manometry, although peristaltic duration might be expected to be prolonged by longitudinal muscle contraction and is the parameter best correlating with a positive edrophonium pain response. ${ }^{17}$ Why edrophonium should cause pain only in individuals with clinical symptoms is unclear, unless the neural pathways responsible for pain perception are already 'sensitised' in these individuals. Perhaps the nociceptors themselves are sensitised in these patients by quite a different mechanism - for instance in response to refluxed gastric acid. There is cer- tainly good precedent for sensitisation in cutaneous mechanonociceptors, ${ }^{38}$ but visceral pain receptors have been little studied in this regard. This would seem to be an important area for future investigation.

This work was presented in part to the British Society of Gastroenterology (Autumn 1990) and has been published as an abstract (Gut 31: A1165). It has also been used in a dissertation submitted by JS de C and accepted by the University of Cambridge for the degree of $M D$.

1 Richter JE, Hackshaw BT, Wu WC, Castell DO. Edrophonium: a useful provocative test for esophageal chest pain. Ann Intern Med 1985; 103: 14-21.

2 Castell DO. Provocative tests in chest pain presumed to be of esophageal origin. Eur $\mathcal{F}$ Gastroenterol Hepatol 1990; 2: 18-20.

3 Katz PO, Dalton CB, Richter JE, Wu WC, Castell DO. Esophageal testing of patients with noncardiac chest pain or dysphagia: results of three years' experience with 1161 patients. Ann Intern Med 1987; 106: 593-7.

4 Lee CA, Reynolds JC, Ouyang A, Baker L, Cohen S. Esophageal chest pain: value of high-dose provocative testing with edrophonium chloride in patients with normal esophageal manometries. Dig Dis Sci 1987; 32: 682-8.

5 London RL, Ouyang A, Snape WJ, Goldberg S, Hirshfeld JW, Cohen S. Provocation of esophageal pain by ergonovine or edrophonium. Gastroenterology 1981; 81: 10-4.

6 Mellow M. Symptomatic diffuse esophageal spasm: manometric follow up and response to cholinergic stimulation and metric follow up and response to cholinergic stimulation and

7 de Caestecker JS, Pryde A, Heading RC. Comparison of intravenous edrophonium and oesophageal acid perfusion during oesophageal manometry in patients with non-cardiac chest pain. Gut 1989; 29: 1029-34

8 Mayer EA, Raybould HE. Role of visceral afferent mechanisms in functional bowel disorders. Gastroenterology 1990; 99: 1688-704.

9 Hertz AF. The sensibility of the alimentary canal in health and disease: lecture I. Lancet 1911; i: 1051-6.

10 Payne WW, Poulton EP. Visceral pain in the upper alimentary tract. $Q \mathcal{F}$ Med 1923; 17: 53-82.

11 Jones CM, Richardson W. Observations on the nature of 'Heart-Burn'. [Abstract]. $\mathcal{F}$ Clin Invest 1926; 2: 610.

12 Polland WS, Bloomfield AL. Experimental referred pain from the gastrointestinal tract. Part 1: the esophagus. $\mathcal{F}$ Clin Invest 1931; 10: 435-52.

13 Lipkin M, Sleisenger MH. Studies of visceral pain: measurements of stimulus intensity and duration associated with the onset of pain in esophagus, ileum and colon. $\mathcal{F}$ Clin Invest 1958; 37: 28-34.

14 Flood CA, Fink S, Mathers J. Pain due to esophageal distension. Am F Dig Dis 1963; 8: 632-8.

15 Kramer P, Hollander W. Comparison of experimental esophageal pain with clinical pain of angina pectoris and esophageal disease. Gastroenterology 1955; 29: 719-43.

16 Baylis JH, Kauntze R, Trounce JR. Observations on distension of the lower end of the oesophagus. $Q \mathcal{F}$ Med 1955; 14: 143-54.

17 Barish CF, Castell DO, Richter JE. Graded esophageal balloon distension: a new provocative test for non-cardiac chest pain. Dig Dis Sci 1986; 31: 1292-8.

18 Deschner WK, Maher KA, Cattau EL, Benjamin SB. Intraesophageal balloon distension versus drug provocation in the evaluation of non-cardiac chest pain. Am $\mathcal{F}$ Gastroenterol 1990; 85: 938-43.

19 Kramer P. Diagnostic value of esophageal balloon distension (letter). Gastroenterology 1989; 96: 271-2

20 Cannon RO, Bonow RO, Bacharach SL, Green MV, Rosing $\mathrm{DR}$, Leon MB, et al. Left ventricular dysfunction in patients with angina pectoris, normal epicardial coronary arteries and

2 abnormal vasodilator reserve. Circulation 1985, 71: 218-26. tion in patients with esophageal chest pain. Gastroenterology 1986; 91: 845-52.

22 Quigley JP, Brody DA. A physiologic and clinical consideration of the pressures developed in the digestive tract. Am 7 Med 1952; 13: 73-81.

23 Andreollo NA, Thompson DG, Kendall GPN, Earlam RJ. Functional relationships between cricopharangeal sphincter and oesophageal body in response to graded intraluminal distension. Gut 1988; 29: 161-6.

24 Christensen J, Lund GE. Esophageal response to distension and electrical stimulation. $\mathcal{f}$ Clin Invest $1969 ; 48$ : 408-19.

25 Winans CS. Alteration of lower esophageal sphincter characteristics with respiration and proximal esophageal balloon distension. Gastroenterology 1972;62: 380-8.

26 Dodds WJ, Hogan WJ, Reid DP, Stewart ET, Arndorfer RC. A comparison between primary esophageal peristalsis following wet and dry swallows. F Appl Physiol 1973; 35: 851-7.

27 Hollis JB, Castell DO. Effect of dry swallows and wet swallows of different volumes on esophageal peristalsis. $\mathcal{F}$ Appl Physiol of different volum

28 Enzmann DR, Harell GS, Zboralske FE. Upper esophageal response to intraluminal distension in man. Gastroenterology 1977; 72: 1292-8.

29 Creamer B, Schegel J. Motor responses of the esophagus to distension. F Appl Physiol 1957; 10: 498-504. 
30 Winship DH, Zboralske FF. The esophageal propulsive force esophageal response to acute obstruction. $\mathcal{F}$ Clin Invest 1967 46: 1391-401.

31 Barish CF, Richter JE, Blackwell JN, Castell DO. Pharmacologic testing of esophageal muscle wall responses to balloon distension in primates [Abstract]. Gastroenterology 1984; 86: 1020 .

32 Flood CA, Fink S. A study of the effect of various drugs on esophageal motility. Gastroenterology 1960; 38: 582-6.

33 Mackenzie J, Belch J, Land D, Park R, McKillip J. Oesophageal ischaemia in motility disorders associated with ches pain. Lancet 1988; ii: 592-5.

34 Rosen AM, Maher KA, Cattau EL, Benjamin S. Esophagea ischemia: does it play a role in non-cardiac chest pain? Gastroenterology 1989; 96: A425.
35 Duda G, Bass B, Huesken JE, Wall S, Harman JW. Ischemia a possible mechanism of esophageal chest pain? Gastroenterology 1989; 96: A132.

36 Sengupta JN, Saha JK, Goyal RK. Stimulus - response function studies of esophageal mechanosensitive nociceptors in sympathetic afferents of opossum. $\mathcal{J}$ Neurophysiol 1990 64: 796-812.

37 Sengupta JN, Kauvar D, Goyal RK. Characteristics of vagal esophageal tension - sensitive afferent fibers in the opossum. F Neurophysiol 1989; 61: 1001-10.

38 Bessou P, Perl ER. Response of cutaneous sensory units with unmyelinated fibres to noxious stimuli. $\mathcal{F}$ Neurophysiol 1969 32: 1025-43. 